\title{
Patterns of Care for Craniopharyngioma: Survey of Members of the American Association of Neurological Surgeons
}

\author{
Todd C. Hankinson ${ }^{a, b}$ Nicholas O. Palmeri ${ }^{\text {e Sarah A. Williams }}{ }^{f}$ \\ Michelle R. Torok ${ }^{b}$ Cesar A. Serrano ${ }^{a}$ Nicholas K. Foreman ${ }^{c}$ \\ Michael H. Handler ${ }^{a}$ Arthur K. Liu ${ }^{d}$ \\ ${ }^{a}$ Pediatric Neurosurgery, Children's Hospital Colorado, University of Colorado Denver, ${ }^{b}$ Children's Outcomes \\ Research Program, University of Colorado Denver, ' Division Neuro-Oncology, Department of Pediatrics, \\ Children's Hospital Colorado, University of Colorado Denver, and dDepartment of Radiation Oncology,

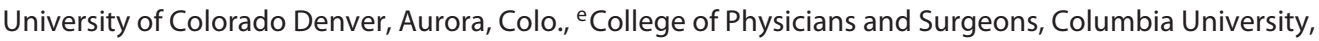 \\ New York, N.Y., and ${ }^{\mathrm{f}}$ Tulane University, New Orleans, La., USA
}

\section{Key Words}

Craniopharyngioma $\cdot$ Resection · Radiation therapy ·

Neurosurgeon

\begin{abstract}
Background: Initial therapy for craniopharyngioma remains controversial. Population-based datasets indicate that traditional algorithms [gross total resection (GTR) vs. subtotal resection (STR) +/- radiation therapy (XRT)] are often not employed. We investigated neurosurgical practice patterns. Methods: A ten-question survey was electronically distributed to members of the American Association of Neurological Surgeons. Responses were analyzed using standard statistical techniques. Results: 102 responses were collected, with a median of 25 craniopharyngiomas managed per respondent. $36 \%$ estimated that their practice included $\geq 75 \%$ pediatric patients and $61 \%$ had an academic practice. $36 \%$ would recommend observation or XRT for a suspected craniopharyngioma in the absence of a tissue diagnosis, with $46 \%$ of these indicating this recommendation in $\geq 10 \%$ of the cases. Following STR, 35\% always recommend XRT and 59\%
\end{abstract}

\section{KARGER}

E-Mail karger@karger.com

www.karger.com/pne recommend it in over half of the cases. However, following STR or biopsy alone, 18 and $11 \%$ never recommend XRT. There was no association between the type of practice (i.e. academic or $\geq 75 \%$ pediatric patients) and practice patterns. Conclusions: This survey verifies that a deviation from established algorithms is common, underscoring the clinical complexity of these patients and recent secondary data analyses. This should influence clinical researchers to investigate outcomes for patients treated using alternative methods. It will lend insight into appropriate treatment options and contribute to quality of life outcomes studies for craniopharyngioma.

(c) 2014 S. Karger AG, Basel

\section{Introduction}

Initial therapy for both adult and pediatric patients with craniopharyngioma has been the subject of considerable controversy. While the most commonly described algorithm centers around the choice between gross total resection (GTR) and subtotal resection (STR) augmented
(C) 2014 S. Karger AG, Basel

1016-2291/14/0493-0131\$39.50/0 
by external beam radiation (XRT), multiple groups promote an individually tailored treatment approach [1-6]. Two recent analyses of the National Cancer Institute's Surveillance, Epidemiology and End Results (SEER) datasets indicate that a significant portion of patients in the United States are not initially treated with GTR or STR + radiation therapy $[7,8]$. While alternative therapeutic regimens, such as intracystic therapy or progression contingent XRT are well established, these data prompted us to further explore the initial practice patterns of neurosurgeons using a brief survey. We intended to survey as broad a population of practicing neurosurgeons as possible, with the knowledge that this would predispose the instrument to a low response rate. We hypothesized that neurosurgeons commonly elect initial treatment strategies other than surgical GTR or STR followed by XRT. Clarification of initial practice patterns not only offers the potential to detail the application of less commonly described approaches, but also contributes to efforts to design clinical outcomes studies for patients with craniopharyngioma.

\section{Methods}

A ten-question survey was designed and then reviewed by the leadership of the Joint Sections of the American Association of Neurological Surgeons (AANS) and the Congress of Neurological Surgeons on Tumors and Pediatric Neurosurgery. The survey was electronically distributed through 2 electronic AANS Special Announcements to 2,974 AANS members in June and July 2012 (see Appendix 1). Results were collected through Zoomerang (SurveyMonkey, Palo Alto, Calif., USA). Statistical analysis was performed using SAS ${ }^{\circledR} 9.3$ (SAS $^{\circledR}$ Institute, Cary, N.C., USA). Frequencies, proportions, and measures of the central tendency were used to describe study results, and $\chi^{2}$ analysis was used to evaluate bivariable associations. Statistical significance was set at a value of $\mathrm{p}<0.05$.

\section{Results}

\section{Characteristics of Respondents}

Responses to 102 surveys (3.4\%) were received. The estimated number of patients with craniopharyngioma that each respondent had assessed during her/his career ranged from 1 to 250 (median $=25$ ), amounting to an estimated total of 2,550 cases. 37 (36.3\%) respondents reported their practice to include $\geq 75 \%$ pediatric patients and $62(60.8 \%)$ described their practice as academic. 32 respondents (31.4\%) completed neurosurgical training between 1977 and 1989, 37 (36.3\%) between 1990 and 1999, and 33 (32.4\%) between 2000 and 2008.
Respondents who described their practices as academic were more likely to report evaluating more than $25 \mathrm{pa}$ tients with craniopharyngioma compared to those in private practice ( 54.8 vs. $22.5 \%, \mathrm{p}=0.001$ ).

\section{Initial Treatment}

In response to the question 'Have you ever recommended observation or treatment without a tissue diagnosis for a patient presenting with a newly diagnosed lesion considered likely to be a craniopharyngioma?' 37 (36.3\%) respondents responded in the affirmative. They reported this recommendation in $0.2-80 \%$ of the cases (median $=5 \%)$, with $17(16.8 \%$ of the total sample $)$ respondents reporting this recommendation in at least $10 \%$ of the cases. Questions 7-9 (see Appendix 1) queried how often respondents recommend XRT immediately following surgery [GTR, STR, and biopsy, respectively]. 100 respondents $(99.0 \%)$ do not recommend XRT in the majority of the cases, in which GTR is achieved. Following STR, $18 \%$ never recommend XRT, $41 \%$ recommend it in half or fewer of the cases, and 35\% always recommend XRT. Following biopsy alone, $56 \%$ always recommend postoperative XRT and $71 \%$ recommend it in $\geq 90 \%$ of the cases. Following biopsy alone, 11/99 (11.1\%) never recommend XRT.

There were no statistically significant differences in the initial treatment patterns of respondents based on the demographic parameters assessed: experience (based on date of training or number of craniopharyngiomas evaluated), practice type, and proportion of practice that is composed of pediatric patients (tables 1,2). Regarding the recommendation for treatment or observation without tissue biopsy, $66.1 \%$ of those in academic practice have never done so and $60.0 \%$ of those in private practice have never done so $(\mathrm{p}=0.53)$.

\section{Discussion}

Craniopharyngioma is a tumor that is well known for the options that exist regarding initial surgical management. While considerable literature compares the merits and limitations of initial GTR versus STR and external beam radiation therapy as the mainstays of initial therapy [5, 9-19], alternative algorithms including intracystic therapies [20-26], progression-contingent XRT [27], and stereotactic radiosurgery [28-31] have also been well described through both primary and secondary data analyses $[7,8,32,33]$. This survey intended to expand on recent secondary data analyses by assessing how commonly al- 


\section{Craniopharyngioma Patterns of Care - Treatment}

- 1. Does your surgical practice consist of $>=75 \%$ pediatric $(<=18 \mathrm{yo})$ patients?

Yes

No

* 2. What year did you complete neurosurgical training?

* 3. Do you work in an academic or private practice setting?

Academic

Private Practice

* 4. Approximately how many patients with craniopharyngioma have you evaluated in your career?

* 5. Have you ever recommended observation or treatment without a tissue diagnosis for a patient presenting with a newly diagnosed lesion considered likely to be a craniopharyngioma?

Yes

No

6. If yes for question 5 , in what percentage of craniopharyngioma patients have you made this recommendation?

- 7. Following a gross total resection of craniopharyngioma, in what percent of cases would you recommend immediate post-operative radiation?

* 8. Following a sub-total resection of craniopharyngioma, if further surgery is not an option, in what percent of cases would you recommend immediate post-operative radiation?

- 9. Following tissue biopsy of craniopharyngioma, if further surgery is not an option, in what percent of cases would you recommend immediate post-operative radiation?

10. If you would like to clarify your answer to any question(s), please do so here

Appendix 1.

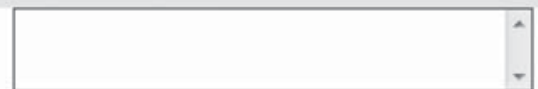

Prev

Submit 
Table 1. Reported likelihood of recommending XRT following STR $(\mathrm{n}=100)$

\begin{tabular}{|c|c|c|c|}
\hline & \multicolumn{2}{|c|}{ Patients } & \multirow[t]{2}{*}{$\mathrm{p}$ value } \\
\hline & $\leq 50 \%$ & $>50 \%$ & \\
\hline \multicolumn{4}{|c|}{ Practice experience } \\
\hline \multicolumn{4}{|c|}{ Year of training completion } \\
\hline $1977-1989$ & 13 & 19 & \\
\hline 1990-1999 & 19 & 17 & \\
\hline $2000-2008$ & 9 & 23 & 0.12 \\
\hline \multicolumn{4}{|c|}{ Number craniopharyngiomas evaluated } \\
\hline $0-25$ & 27 & 31 & \\
\hline $30-250$ & 14 & 28 & 0.19 \\
\hline \multicolumn{4}{|c|}{ Practice character } \\
\hline \multicolumn{4}{|c|}{ Proportion of pediatric patients } \\
\hline$\geq 75 \%$ & 11 & 25 & \\
\hline$<75 \%$ & 30 & 34 & 0.11 \\
\hline \multicolumn{4}{|l|}{ Practice setting } \\
\hline Academic & 22 & 40 & \\
\hline Private & 19 & 19 & 0.15 \\
\hline
\end{tabular}

ternative algorithms are employed by contemporary neurosurgeons. We found that many patients are managed with algorithms that differ from the pattern of GTR or STR + XRT. While not statistically significant, there was a trend of neurosurgeons who completed training between 2000 and 2008 to employ XRT following STR or biopsy at greater rates than their more senior colleagues (tables 1,2). This may reflect a practice trend towards greater use of XRT, but further studies are required to more clearly address this question. We were surprised to find that 18 and $11 \%$ of respondents never recommend XRT immediately following STR or tumor biopsy, respectively. Additionally, 36.3\% (37/102) of respondents indicated that they had treated or observed a patient with a presumptive craniopharyngioma without a biopsy. Although not a direct comparison, this is consistent with the rates of $12.7-20.8 \%$ of patients identified from the SEER datasets as receiving neither surgery nor XRT at the time of diagnosis with craniopharyngioma $[7,8]$. However, such practice patterns are in distinction to reports from multiple high volume centers, in which all reported patients were treated with surgery, with or without postoperative XRT [5, 14, 16, 19]. Furthermore, recent systematic reviews $[10,11]$, while they provide excellent insight regarding comparative outcomes, focus on patients who were treated operatively, thereby excluding what may be a substantial subset of patients.
Table 2. Reported likelihood of recommending XRT following biopsy $(\mathrm{n}=99)$

\begin{tabular}{lll}
\hline & Patients & p value \\
\hline$\leq 50 \%$ & $>50 \%$ & \\
\hline
\end{tabular}

Practice experience

Year of training completion

$\begin{array}{ccc}1977-1989 & 6 & 26 \\ 1990-1999 & 10 & 26 \\ 2000-2008 & 4 & 27 \\ \text { mber craniopharyngiomas evaluated } & \\ 0-25 & 14 & 43 \\ 30-250 & 6 & 36\end{array}$

Number craniopharyngiomas evaluated

$$
30-250
$$

\begin{tabular}{lrrr}
\hline Practice character & & & \\
Proportion of pediatric patients & & \\
$\quad 275 \%$ & 6 & 30 & \\
$\quad<75 \%$ & 14 & 49 & 0.51 \\
Practice setting & & & \\
$\quad$ Academic & 12 & 50 & \\
$\quad$ Private & 8 & 29 & 0.79 \\
\hline
\end{tabular}

These results are significant because they reinforce the concept that therapy for patients with craniopharyngioma is often individually tailored [2-6]. Furthermore, variability in initial treatment algorithms must be incorporated into the design and interpretation of high-quality clinical outcomes studies for patients with craniopharyngioma. While recent analyses of large retrospective datasets have associated posttreatment morbidity/mortality with factors such as surgical experience [34], the extent of resection [34], the age at presentation [18], tumor size [19], and hydrocephalus [18, 19], these conclusions are limited by the bias associated with their data sources, which include data collected over a wide time range [18], pooled data [34], and a study design focused on the difference in outcomes between primary and recurrent craniopharyngioma treatment [19].

While randomized clinical trials for craniopharyngioma are logistically challenging [35], pragmatically designed multicenter registries offer the opportunity for both retrospective data analysis using consistent definitions and prospective data collection. The trinational KRANIOPHARYNGEOM 2000 study collected observational data from 46 centers [36]. Among their findings, the authors identified low 3-year event-free survival rates in both the completely (EFS 0.64) and incompletely (EFS 0.31) resected populations. The subsequent study, KRANIOPHARYNGEOM 2007, includes ran- 
domization of a subset of patients in an effort to ascertain the optimal timing of XRT, following incomplete surgical resection in children over 5 years of age [37]. Currently, there is no equivalent multicenter study ongoing in North America.

Despite the limited scope of this survey instrument and recognition that our highly diverse surveyed population would likely yield a low response rate, the response rate of $3.4 \%$ was suboptimal. As a result, response bias may lead to conclusions that are not generalizable. This point is demonstrated by a bias in the respondents towards both academic (60.8\%) and pediatric (36.3\%) practices. Nevertheless, the data represent the practice patterns of over 100 neurosurgeons and represent a large range of experience based on the years in practice and number of craniopharyngiomas assessed. Additionally, with nearly $40 \%$ of the respondents practicing outside an academic environment, we feel that these data do represent both the academic and private practice environments. A larger sample would be unlikely to refute the conclusion that a variety of approaches are used in the initial treatment of patients with craniopharyngioma. A second limitation of this work resulted from our effort to simplify the questionnaire as much as possible. This presented challenges to the respondents by limiting their capacity to answer with the optimal level of detail. Specific concerns resulted from our choices to exclude questions regarding the use of intracavitary therapy and to not rigidly define a time frame for immediate postoperative' XRT. The latter decision was made to allow respondents the freedom to express their intent regarding the timing of therapeutic recommendations. Future clinical outcomes studies will allow for more detailed responses.

\section{Conclusions}

Using a streamlined survey instrument that gathered data from members of the AANS, we verified recent study results indicating that many patients with craniopharyngioma receive initial treatment that is tailored to the clinical situation, often deviating from the most common algorithm: GTR versus STR and XRT [7, 8]. This finding verifies that a deviation from this algorithm is common and should influence clinical researchers to investigate and document the outcomes of patients who are treated using alternative methods. This will not only lend insight into appropriate treatment options, but will contribute to the design of the prospective quality of life outcomes studies for patients with craniopharyngioma. Given the rarity of this tumor, pragmatic trial designs that accommodate less restrictive treatment algorithms will be necessary in order to complete such studies.

\section{Acknowledgement}

This work was supported in part by NIH/NCRR Colorado CTSI Grant No. UL1 RR025780. Contents are the authors' sole responsibility and do not necessarily represent official NIH views. This work was supported in part by the Morgan Adams Foundation.

\section{References}

1 De Vile CJ, Grant DB, Kendall BE, Neville BG, Stanhope R, Watkins KE, Hayward RD: Management of childhood craniopharyngioma: can the morbidity of radical surgery be predicted? J Neurosurg 1996;85:73-81.

2 Flitsch J, Muller HL, Burkhardt T: Surgical strategies in childhood craniopharyngioma. Front Endocrinol (Lausanne) 2011;2:96.

-3 Meuric S, Brauner R, Trivin C, Souberbielle JC, Zerah M, Sainte-Rose C: Influence of tumor location on the presentation and evolution of craniopharyngiomas. J Neurosurg 2005;103(5 suppl):421-426.

-4 Puget S, Garnett M, Wray A, Grill J, Habrand JL, Bodaert N, Zerah M, Bezerra M, Renier D, Pierre-Kahn A, Sainte-Rose C: Pediatric craniopharyngiomas: classification and treatment according to the degree of hypothalamic involvement. J Neurosurg 2007;106(1 suppl): 3-12.
5 Sainte-Rose C, Puget S, Wray A, Zerah M, Grill J, Brauner R, Boddaert N, Pierre-Kahn A: Craniopharyngioma: the pendulum of surgical management. Childs Nerv Syst 2005;21: 691-695.

6 Van Gompel JJ, Nippoldt TB, Higgins DM, Meyer FB: Magnetic resonance imaginggraded hypothalamic compression in surgically treated adult craniopharyngiomas determining postoperative obesity. Neurosurg Focus 2010;28:E3.

-7 Hankinson TC, Fields EC, Torok MR, Beaty BL, Handler MH, Foreman NK, O’Neill BR, Liu AK: Limited utility despite accuracy of the national SEER dataset for the study of craniopharyngioma. J Neurooncol 2012;110:271-278.

8 Zacharia BE, Bruce SS, Goldstein H, Malone HR, Neugut AI, Bruce JN: Incidence, treatment and survival of patients with craniopharyngioma in the surveillance, epidemiology and end results program. Neuro Oncol 2012; 14:1070-1078.

-9 Baskin DS, Wilson CB: Surgical management of craniopharyngiomas. A review of 74 cases. J Neurosurg 1986;65:22-27.

10 Clark AJ, Cage TA, Aranda D, Parsa AT, Auguste KI, Gupta N: Treatment-related morbidity and the management of pediatric craniopharyngioma: a systematic review. J Neurosurg Pediatr 2012;10:293-301.

11 Clark AJ, Cage TA, Aranda D, Parsa AT, Sun PP, Auguste KI, Gupta N: A systematic review of the results of surgery and radiotherapy on tumor control for pediatric craniopharyngioma. Childs Nerv Syst 2013;29:231238.

12 Fahlbusch R, Honegger J, Paulus W, Huk W, Buchfelder M: Surgical treatment of craniopharyngiomas: experience with 168 patients. J Neurosurg 1999;90:237-250. 
13 Fraioli MF, Santoni R, Fraioli C, Contratti F: 'Conservative' surgical approach and early postoperative radiotherapy in a patient with a huge cystic craniopharyngioma. Childs Nerv Syst 2006;22:151-155; discussion 158-163.

14 Merchant TE, Kiehna EN, Sanford RA, Mulhern RK, Thompson SJ, Wilson MW, Lustig RH, Kun LE: Craniopharyngioma: the St. Jude Children's Research Hospital experience 1984-2001. Int J Radiat Oncol Biol Phys 2002; 53:533-542.

15 Prieto R, Pascual JM, Subhi-Issa I, Jorquera M, Yus M, Martinez R: Predictive factors for craniopharyngioma recurrence: a systematic review and illustrative case report of a rapid recurrence. World Neurosurg 2013;79:733749.

16 Winkfield KM, Tsai HK, Yao X, Larson E, Neuberg D, Pomeroy SL, Ullrich NJ, Cohen LE, Kieran MW, Scott RM, Goumnerova LC, Marcus KJ: Long-term clinical outcomes following treatment of childhood craniopharyngioma. Pediatr Blood Cancer 2011;56:11201126.

17 Zuccaro G: Radical resection of craniopharyngioma. Childs Nerv Syst 2005;21:679-690.

18 Gautier A, Godbout A, Grosheny C, Tejedor I, Coudert M, Courtillot C, Jublanc C, De Kerdanet M, Poirier JY, Riffaud L, Sainte-Rose C, Van Effenterre R, Brassier G, Bonnet F, Touraine P: Markers of recurrence and longterm morbidity in craniopharyngioma: a systematic analysis of 171 patients. J Clin Endocrinol Metab 2012;97:1258-1267.

19 Elliott RE, Hsieh K, Hochm T, BelitskayaLevy I, Wisoff J, Wisoff JH: Efficacy and safety of radical resection of primary and recurrent craniopharyngiomas in 86 children. J Neurosurg Pediatr 2010;5:30-48.

20 Albright AL, Hadjipanayis CG, Lunsford LD, Kondziolka D, Pollack IF, Adelson PD: Individualized treatment of pediatric craniopharyngiomas. Childs Nerv Syst 2005;21:649654.
21 Barriger RB, Chang A, Lo SS, Timmerman RD, DesRosiers C, Boaz JC, Fakiris AJ: Phosphorus-32 therapy for cystic craniopharyngiomas. Radiother Oncol 2011;98:207-212.

22 Cavalheiro S, Di Rocco C, Valenzuela S, Dastoli PA, Tamburrini G, Massimi L, Nicacio JM, Faquini IV, Ierardi DF, Silva NS, Pettorini BL, Toledo SR: Craniopharyngiomas: intratumoral chemotherapy with interferon-alpha: a multicenter preliminary study with 60 cases. Neurosurg Focus 2010;28:E12.

23 Hukin J, Steinbok P, Lafay-Cousin L, Hendson G, Strother D, Mercier C, Samson Y, Howes W, Bouffet E: Intracystic bleomycin therapy for craniopharyngioma in children: the Canadian experience. Cancer 2007;109: 2124-2131.

24 Voges J, Sturm V, Lehrke R, Treuer H, Gauss C, Berthold F: Cystic craniopharyngioma: long-term results after intracavitary irradiation with stereotactically applied colloidal beta-emitting radioactive sources. Neurosurgery 1997;40:263-269; discussion 269-270.

-25 Yeung JT, Pollack IF, Panigrahy A, Jakacki RI: Pegylated interferon-alpha-2b for children with recurrent craniopharyngioma. J Neurosurg Pediatr 2012;10:498-503.

26 Jakacki RI, Cohen BH, Jamison C, Mathews VP, Arenson E, Longee DC, Hilden J, Cornelius A, Needle M, Heilman D, Boaz JC, Luerssen TG: Phase II evaluation of interferon-alpha-2a for progressive or recurrent craniopharyngiomas. J Neurosurg 2000;92:255-260.

27 Müller HL, Gebhardt U, Pohl F, Flentje M, Emser A, Warmuth-Metz M, Kolb R, Calaminus G, Sörensen N: Relapse pattern after complete resection and early progression after incomplete resection of childhood craniopharyngioma. Klin Padiatr 2006;218:315-320.

28 Kobayashi T: Long-term results of gamma knife radiosurgery for 100 consecutive cases of craniopharyngioma and a treatment strategy. Prog Neurol Surg 2009;22:63-76.

29 Park YS, Chang JH, Park YG, Kim DS: Recurrence rates after neuroendoscopic fenestration and gamma knife surgery in comparison with subtotal resection and gamma knife surgery for the treatment of cystic craniopharyngiomas. J Neurosurg 2011;114:1360-1368.
30 Veeravagu A, Lee M, Jiang B, Chang SD: The role of radiosurgery in the treatment of craniopharyngiomas. Neurosurg Focus 2010; 28:E11.

31 Xu Z, Yen CP, Schlesinger D, Sheehan J: Outcomes of gamma knife surgery for craniopharyngiomas. J Neurooncol 2011;104:305313.

- 32 Elliott RE, Jane JA Jr, Wisoff JH: Surgical management of craniopharyngiomas in children: meta-analysis and comparison of transcranial and transsphenoidal approaches. Neurosurgery 2011;69:630-643; discussion 643.

33 Fang Y, Cai BW, Zhang H, Liu W, Wu B, Xu JG, You C: Intracystic bleomycin for cystic craniopharyngiomas in children. Cochrane Database Syst Rev 2012;4:CD008890.

34 Sughrue ME, Yang I, Kane AJ, Fang S, Clark AJ, Aranda D, Barani IJ, Parsa AT: Endocrinologic, neurologic, and visual morbidity after treatment for craniopharyngioma. J Neurooncol 2011;101:463-476.

35 Wisoff JH: Commentary: intracystic bleomycin for cystic craniopharyngiomas in children (abridged republication of cochrane systematic review). Neurosurgery 2012;71:E1063E1064.

-36 Müller HL, Gebhardt U, Schröder S, Pohl F, Kortmann RD, Faldum A, Zwiener I, Warmuth-Metz M, Pietsch T, Calaminus G, Kolb R, Wiegand C, Sörensen N: Analyses of treatment variables for patients with childhood craniopharyngioma - results of the multicenter prospective trial KRANIOPHARYNGEOM 2000 after three years of follow-up. Horm Res Paediatr 2010;73:175-180.

37 Muller HL: KRANIOPHARYNGEOM 2007: multicenter prospective study of children and adolescents with craniopharyngioma. http://www.kinderkrebsinfo.de/sites/ kinderkrebsinfo/content/e1676/e9032/ e1758/e28472/download67843/KRANIO PHARYNGEOM2007_english_3._ger.pdf (accessed August 12, 2013). 